\title{
Spastiškumo sąsajos su neuropatiniu skausmu pacientams, sergantiems išsẻtine skleroze
}

\section{B. Afanasjeva* \\ R. Balnyté**}

*Lietuvos sveikatos mokslu universitetas, Medicinos fakultetas

**Lietuvos sveikatos mokslu universiteto ligonine

Kauno klinikos,

Neurologijos klinika
Santrauka. I vadas. Išsėtinè sklerozè (IS) - tai lètinè uždegiminė autoimuninė demielinizuojanti centrinès nervų sistemos liga. Spastiškumas yra viena iš neigalumą sukeliančių komplikacijų pacientams, sergantiems šia liga, ir gali turèti ịtakos neuropatinio skausmo atsiradimui, kurie kartu dar labiau sutrikdo paciento kasdienę veiklą.

Tiriamieji ir tyrimo metodai. Buvo tiriami pacientai, sergantys IS. Sergančiųjų IS negalia vertinta naudojant išplèstinę negalios vertinimo skalę (EDSS), spastiškumas - naudojant modifikuotą Ashworth spastiškumo skalę, neuropatinis skausmas - naudojant neuropatinio skausmo diagnostikos klausimyną (DN4).

Rezultatai. Tyrime dalyvavo 59 pacientai. Tiriamųjų grupę sudare 39 moterys ir 20 vyrų. Tiriamieji sirgo recidyvuojančia remituojančia - 52 pacientai $(88,1 \%)$, progresuojančia 7 (11,9\%) IS ligos formomis. Lyginant ligos formas, didesnis negalios laipsnis buvo nustatytas sergantiesiems progresuojančia ligos forma - 6,36 $\pm 1,38$, o sergantiesiems recidyvuojančia remituojančia ligos forma $-4,38 \pm 1,4(\mathrm{p}=0,001)$. Spastiškumas nustatytas $35(59,3 \%)$ pacientams, sergantiems IS. Jo lokalizacija $(\mathrm{N}=35)$ : per alkūnės sąnari - $2(5,71 \%)$, kelio sąnarị - $27(77,14 \%)$, alkūnès ir kelio sąnarị - 6 (17,15\%). Neuropatinis skausmas nustatytas 33 pacientams $(55,9 \%)$, skausmo lokalizacija: viršutinèse galūnèse - $5(15,15 \%)$, apatinèse galūnėse - $23(69,7 \%)$, abiejose galūnèse - $5(15,15 \%)$. Moterims $(\mathrm{N}=39 ; 61,54 \%)$ spastiškumas buvo nustatomas dažniau nei vyrams $(N=20 ; 55 \%)(p=0,42)$. Neuropatinio skausmo pobūdis: deginantis - 18 (30,5\%), primena skausmingą šalimą - $14(23,7 \%)$, elektros srovès plitimą - $11(18,6 \%)$. Pacientai, kurie turèjo spastiškumą, dažniau skundèsi neuropatiniu skausmu $(r=0,655, p=0,0001)$. Nustatytas didesnis spastiškumas gali būti susijęs su didesniu skausmo intensyvumu $(r=0,536, p=0,0001)$. Spastiškumo vieta gali būti susijusi su neuropatinio skausmo vieta, nes sąnaryje, kuriame buvo nustatytas spastiškumas, buvo jaučiamas ir skausmas $(\mathrm{p}=0,0001)$.

Išvados. Tirti pacientai IS susirgo vyresniame amžiuje. Didesnė dalis tiriamujų sirgo recidyvuojančia remituojančia ligos forma, o sergančiųų progresuojančia forma negalia buvo didesnè. Spastiškumas pasireiškė daugiau nei pusei tiriaműjų, sergančių IS. Neuropatinis skausmas dažniausiai nustatytas apatinėse, rečiau - viršutinėse galūnėse. Pacientai dažniausiai jautė deginančio pobūdžio skausmą, rečiau - skausmingo šalimo ir elektros srovès plitimo pojūčio skausmą. Pacientams, kuriems nustatytas spastiškumas, dažniau pasireiškè neuropatinis skausmas. Didesnis spastiškumas gali būti susijęs su didesniu skausmo intensyvumu, o spastiškumo vieta - su neuropatinio skausmo vieta.

Raktažodžiai: išsėtinė sklerozè, spastiškumas, neuropatinis skausmas.

\section{Adresas:}

Brigita Afanasjeva

Lietuvos sveikatos mokslu universitetas, Medicinos fakultetas

Tvirtovés al. 2-18, LT-50169 Kaunas

El.paštas b.afanasjeva@gmail.com

\section{IVADAS}

Išsėtinė sklerozė (IS) - tai lètinė uždegiminė autoimuninė demielinizuojanti centrinés nervų sistemos liga, pasireiškianti recidyvuojančiais arba nuolat progresuojančiais neurologinių funkcijų sutrikimo simptomais, ilgainiui sukeliančiais negalią. Dažniausiai serga jauni žmonès [1-3]. Spastiškumas yra viena iš neiggalumą sukeliančių kompli-

(C) Neurologijos seminarai, 2019. Open Access. This article is distributed under the terms of the Creative Commons Attribution 4.0 International License CC-BY 4.0 (http://creativecommons.org/licenses/by/4.0/), which permits unrestricted use, distribution, and reproduction in any medium, provided you give appropriate credit to the original author(s) and the source, provide a link to the Creative Commons license, and indicate if changes were made. 
kacijų pacientams, sergantiems šia liga $[4,5]$. Kartu su spastiškumu dažniausiai pasireiškia ir judesių sutrikimai, miego sutrikimas, raumenų spazmai, nuovargis ir neuropatinis skausmas [5, 6]. Neuropatinis skausmas - vienas iš dažniausių simptomų, sergant IS, kuris sunkina paciento gyvenimo kokybę ir yra sudettingai gydomas [7]. Toks skausmas dažniau pasireiškia moterims ir turi ryši su emocine būsena (depresija ir nuovargiu). Išsėtine skleroze sergantys pacientai, kurie taip pat serga ir depresija, dažniau jaučia neuropatinį skausmą. Nuovargis yra dažnas simptomas, sergant IS, ir turi didelę reikšmę suprastejjusiai gyvenimo kokybei. Nuovargiui atsirasti įtakos turi neuropatinis skausmas [8]. Spastiškumas gali turèti įtakos neuropatinio skausmo atsiradimui, kurie kartu dar labiau sutrikdo paciento kasdienę veiklą. Spastiškumo ir neuropatinio skausmo sąsajos radimas padès pacientams skirti tinkamą gydymą ir pagerinti gyvenimo kokybę, nes, sumažinus spastiškumą, sumažeja ir skausmas.

\section{DARBO TIKSLAS}

İvertinti spastiškumo sąsajas su neuropatiniu skausmu pacientams, sergantiems išsėtine skleroze.

\section{TIRIAMIEJI IR TYRIMO METODAI}

Tyrimui atlikti buvo gautas bioetikos leidimas Nr. BEC-MF-61. Buvo ištirti 59 pacientai, sergantys IS, kurie gydèsi LSMU Kauno klinikų Neurologijos klinikoje ir kuriems buvo pateikta anoniminė anketa.

İtraukimo kriterijai: pacientai, sergantys išsėtine skleroze, kurie buvo tirti ir gydèsi LSMU Neurologijos klinikoje 201711 - 2018 02, kuriems išsètinė sklerozė buvo nustatyta ir patvirtinta atnaujintais McDonaldo kriterijais (2017) [9].

Neitraukimo (atmetimo) kriterijai: pacientai, kuriems buvo neaiški ar nepatvirtina išsėtinès sklerozès diagnozè, turèję gretutinių ligų (onkologinės ligos, traumos, metabolizmo sutrikimai (cukrinis diabetas), kraujagyslių ligos).

\section{Instrumentai (skalès)}

Sergančiųjų IS negalia vertinta naudojant išplèstinę negalios vertinimo skalę (angl. Expanded Disability Status Scale, EDSS). Spastiškumas vertintas per abiejų pusių alkūnès, kelio sąnarius, naudojant modifikuotą Ashworth spastiškumo skalę. Neuropatinis skausmas vertintas nau- dojant neuropatinio skausmo diagnostikos klausimyną (DN4).

\section{Statistinis duomenų apdorojimas}

Statistinè duomenu analizė atlikta su „Microsoft Excel“ ir SPSS 23.0 programomis. Apskaičiuotos procentinès dydžių reikšmès (\%). Statistinis ryšys vertintas taikant Chi kvadrato testą. Vidurkiams lyginti buvo naudojamas Stjudento t kriterijus. Koreliacijoms ịvertinti naudoti Kendall's ir Pearson koreliacijos koeficientai. Skirtumai laikyti statistiškai reikšmingi, kai $\mathrm{p}<0,05$.

\section{REZULTATAI}

Tyrime dalyvavo 59 pacientai. Tiriamųjų grupę sudarè 39 moterys ir 20 vyrų, kurie sirgo recidyvuojančia remituojančia (RR) - $52(88,1 \%)$, progresuojančia - 7 (11,9\%) IS ligos formomis. Pacientų amžiaus vidurkis $48,4 \pm 13,55 \mathrm{~m}$. Ligos trukmė nuo pirmųjų simptomų atsiradimo pradžios (metais) - 10,81 $\pm 7,18$. Sergančiųjų išsėtine skleroze amžiaus vidurkis metais $-37,59 \pm 13,41$. Negalia tyrimo metu buvo 4,6 $\pm 1,53$ (pagal EDSS). Lyginant ligos formas, didesnis negalios laipsnis buvo nustatytas sergantiesiems progresuojančia ligos forma - 6,36 $\pm 1,38$, o sergantiesiems RR ligos forma negalios laipsnis $4,38 \pm 1,4(p=0,001)$.

Spastiškumas nustatytas $35(59,3 \%)$ sergantiems IS pacientams. Spastiškumo lokalizacija $(\mathrm{N}=35)$ : per alkūnès sąnari - $2(5,71 \%)$, per kelio sąnarị - $27(77,14 \%)$, per alkūnès ir kelio sąnari - 6 (17,15\%). Sergantiesiems IS buvo nustatytas vidutinis spastiškumo dydis $-2,12 \pm 2,74$ (mažiausiai - 0 balų; daugiausiai - 12 balų). Neuropatinis skausmas nustatytas 33 pacientams $(55,9 \%)$, vidutinis neuropatinis skausmas - 2,15 $\pm 2,51$ (mažiausias - 0 balų; didžiausias -8 balų). Neuropatinio skausmo lokalizacija $(\mathrm{N}=33)$ : viršutinèse galūnėse - $5(15,15 \%)$, apatinèse galūnėse - $23(69,7 \%)$, abiejose galūnèse - $5(15,15 \%)$. Spastiškumo ir neuropatinio skausmo lokalizacija pateikiama lenteleje.

61,54 \% moterų ir $55 \%$ vyrų skundèsi spastiškumu, procentinis spastiškumo pasiskirstymas tarp lyčių statistiškai nesiskyrè $(p=0,42)$. Neuropatinio skausmo pobūdis: deginantis - $18(30,5 \%)$, primena skausmingą šalimą $14(23,7 \%)$, primena elektros srovès plitimą - $11(18,6 \%)$ (pav.).

Pacientai, kurie turëjo spastiškumą, dažniau skundėsi neuropatiniu skausmu $(\mathrm{r}=0,655, \mathrm{p}=0,0001)$. Nustatytas didesnis spastiškumas gali būti susijęs su didesniu skaus-

Lentelè. Spastiškumo ir neuropatinio skausmo lokalizacija

\begin{tabular}{||l|c|l|c||}
\hline & Spastiškumo lokalizacija (\%) & & Neuropatinio skausmo vieta (\%) \\
\hline Alkūnės sąnarys & 5,71 & Viršutinės galūnės & 15,15 \\
\hline Kelio sąnarys & 77,14 & Apatinės galūnės & 69,7 \\
\hline Abu sąnariai & 17,15 & Abi galūnės & 15,15 \\
\hline
\end{tabular}




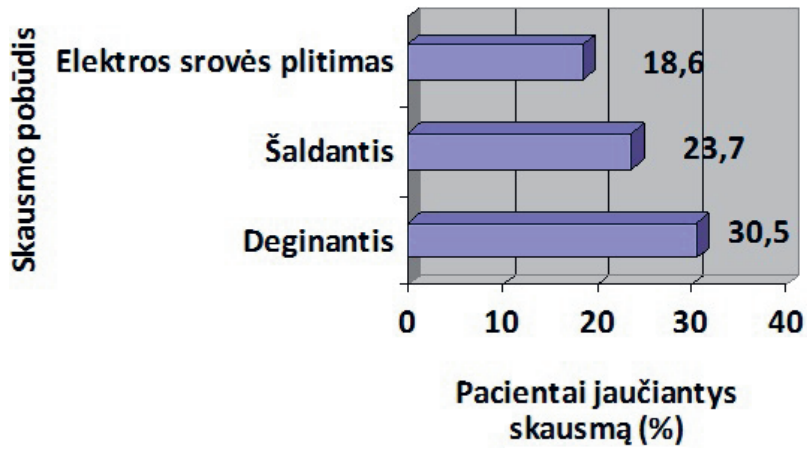

Pav. Neuropatinio skausmo pobūdis

mo intensyvumu $(r=0,536, p=0,0001)$. Spastiškumo vieta gali būti susijusi su neuropatinio skausmo vieta, nes sąnaryje, kuriame buvo nustatytas spastiškumas, buvo jaučiamas ir skausmas $(p=0,0001)$.

\section{REZULTATU APTARIMAS}

Lietuvoje nèra atlikta tyrimų, kurie analizuotų spastiškumo sąsają su neuropatiniu skausmu, sergant išsettine skleroze, todèl šio tyrimo rezultatai galètų būti reikšmingi ir naudingi klinikiniame darbe, gydant spastiškumą ir neuropatinị skausmą. Tiriamų sergančiųjų IS grupę sudarė 59 pacientai, tačiau didesnès tiriamųų grupès padètų surinkti tikslesnius ir aiškesnius duomenis apie spastiškumo ir neuropatinio skausmo sutrikimų sąsajas.

Didžioji dalis tiriamujų buvo moterys, taip pat ir literatūroje yra teigiama, kad moterys serga dažniau nei vyrai [10-12]. Didžiają dali tiriamųjų sudarè pacientai, kurie sirgo RR ligos forma $(88,1 \%)$. Literatūros duomenimis, dažnesnè forma ir yra nustatoma RR [13]. Remiantis šiais duomenimis, didžioji dalis tiriamųjų, kurie sirgo išsètine skleroze, skundėsi spastiškumu. Taip pat ir mūsų atliktame tyrime daugiau nei pusei pacientų, sergančių IS, buvo nustatytas spastiškumas. Spastiškumas dažniausiai pasireiškia apatinėse galūnėse, tačiau gali būti ir viršutinėse. Mūsų atliktame tyrime dažniausiai buvo apatinèse galūnèse [5, 14]. Atliktame tyrime neuropatinis skausmas pasireiškẻ daugiau nei pusei tiriamujų dažniausiai, kaip minèta, buvo apatinèse galūnėse, dažniausias pobūdis - deginantis. Literatūros duomenimis, neuropatinis skausmas randamas daugiau nei pusei tiriamųų ir yra dažnesnis, sergant progresuojančiomis ligos formomis, taip pat dažnesnis jaunesniems žmonėms $[5,15,16]$. Literatūroje nurodomas neuropatinio skausmo pobūdis dažniausiai yra elektros srovès plitimo, antroje vietoje - deginantis [17]. Remiantis autorių nuomone, neuropatinis skausmas yra susijęs su spastiškumu. Kuo didesnis skausmas, tuo didesnis ir spastiškumas. Tai parodo, kad neuropatinis skausmas ir spastiškumas yra glaudžiai susiję: galūnèje, kurioje yra didesnis spastiškumas, progresuoja ir neuropatinis skausmas $[16,17]$.

Vieni autoriai teigia, kad jų atliktame tyrime pacientai, kurie skundèsi didesnio laipsnio spastiškumu, skundèsi ir didesniu skausmu [14]. Kito atlikto tyrimo autoriai teigia, kad pacientams, kuriems buvo efektyvus spastiškumo gydymas, taip pat sumažèjo ir skausmas [12, 18]. Literatūros duomenimis, spastiškumas gali sukelti skausmą. Šią hipotezę įrodè ir mūsų atliktas tyrimas: neuropatinis skausmas buvo stebimas tose pačiose galūnėse, kur buvo nustatytas spastiškumas [14, 16-18]. Šiai hipotezei (spastiškumas turi įtakos neuropatiniui skausmui atsirasti) patvirtinti reikètų daugiau išnagrinèti spastiškumo ir neuropatinio skausmo atsiradimo mechanizmus, labiau išsiaiškinti, kada atsirado spastiškumas ir kada - skausmas, kad būtų galima patikimiau patvirtinti ar paneigti šią sąsają. S. R. Andresen, F. Biering-Sørensen ir kiti atlikto tyrimo autoriai teigia, kad tarp spatiškumo ir neuropatinio skausmo yra ryšys, todèl labai svarbu atlikti daugiau tyrimų šia tema [18].

Spastiškumo ir neuropatinio ryšio radimas gali padèti pagerinti sergančiujų IS gyvenimo kokybę, nes pacientai, jaučiantys spastiškumą ir neuropatinị skausmą, dažniau skundžiasi nuovargiu ir depresija. Šio tyrimo metu nebuvo vertinta pacientų gyvenimo kokybė, tačiau, remdamiesi literatūra, galime teigti, kad pacientai, kurie skundèsi spastiškumu ir neuropatiniu skausmu, dažniau skundèsi blogesne gyvenimo kokybe, dažnesniu nuovargiu ir bloga nuotaika $[14,16,18]$. Taigi, atradę šią sąsają, galèsime skirti efektyvesnị gydymą ir pagelbèsime pacientams kasdieniame jų gyvenime.

\section{IŠVADOS}

Tirti pacientai IS susirgo vyresniame amžiuje. Didesnè dalis tiriamujų sirgo recidyvuojančia remituojančia ligos forma. Pacientų, sergančių progresuojančia forma, negalia buvo didesnè. Spastiškumas pasireiškẻ daugiau nei pusei tiriamųjų, sergančiu IS. Neuropatinis skausmas dažniausiai nustatytas apatinėse, rečiau - viršutinėse galūnėse. Pacientai dažniau jautė deginančio pobūdžio skausmą, rečiau - skausmingo šalimo ir elektros srovès plitimo pojūčio skausmą. Pacientams, kuriems nustatytas spastiškumas, dažniau pasireiškè ir neuropatinis skausmas. Didesnis spastiškumas gali būti susijęs su didesniu skausmo intensyvumu, o spastiškumo vieta gali būti susijusi su neuropatinio skausmo vieta.

\section{Literatūra}

1. Novotna A, Mares J, Ratcliffe S, Novakova I, Vachova M, Zapletalova O, et al. A randomized, double-blind, placebocontrolled, parallel-group, enriched-design study of nabiximols (Sativex $\left.{ }^{\circledR}\right)$, as add-on therapy, in subjects with refractory spasticity caused by multiple sclerosis. Eur J Neurol 2011, 18(9): 1122-31. https://doi.org/10.1111/ j.1468-1331.2010.03328.x

2. Patejdl R, Zettl UK. Spasticity in multiple sclerosis: contribution of inflammation, autoimmune mediated neuronal damage and therapeutic interventions. Autoimmun Rev 2017; 16(9): 925-36. https://doi.org/10.1016/j.autrev.2017. 07.004 
3. Disanto G, Berlanga AJ, Handel AE, Para AE, Burrell AM, Fries A, et al. Heterogeneity in multiple sclerosis: scratching the surface of a complex disease. Autoimmune Dis 2010; 2011: 932351. https://doi.org/10.4061/2011/932351

4. Izquierdo G. Multiple sclerosis symptoms and spasticity management: new data. Neurodegener Dis Manag 2017; 7(6s): 7-11. https://doi.org/10.2217/nmt-2017-0034

5. Rice J, Cameron M. Cannabinoids for treatment of MS symptoms: state of the evidence. Curr Neurol Neurosci Rep 2018; 18(8): 50. https://doi.org/10.1007/s11910-018-0859-x

6. Collongues N, Vermersch P. Multiple sclerosis spasticity: 'state-of-the-art' questionnaire survey of specialized healthcare professionals. Expert Rev Neurother 2013; 13(3 Suppl 1): 21-5. https://doi.org/10.1586/ern.13.10

7. Duffy SS, Lees JG, Perera CJ, Moalem-Taylor G. Managing neuropathic pain in multiple sclerosis: pharmacological interventions. Med Chem 2018; 14(2): 106-19. https://doi.org/ $10.2174 / 1573406413666170906122508$

8. Heitmann H, Biberacher V, Tiemann L, et al. Prevalence of neuropathic pain in early multiple sclerosis. Mult Scler 2016; 22(9): 1224-30. https://doi.org/10.1177/1352458515613643

9. Thompson AJ, Banwell BL, Barkhof F. Diagnosis of multiple sclerosis: 2017 revisions of the McDonald criteria. Lancet Neurol 2018; 17(2): 162-73. https://doi.org/10.1016/ S1474-4422(17)30470-2

10. Melcon MO, Correale J, Melcon CM. Is it time for a new global classification of multiple sclerosis? J Neurol Sci 2014; 344: 171-81. https://doi.org/10.1016/j.jns.2014.06.051

11. Olek MJ, Mowry E. Pathogenesis and epidemiology of multiple sclerosis. https://www.uptodate.com/contents/ pathogenesis-and-epidemiology-of-multiple-sclerosis. Accessed May 2019.

12. Rog DJ, Nurmikko TJ, Friede T, Young CA. Randomized, controlled trial of cannabis-based medicine in central pain in multiple sclerosis. Neurology 2005; 65(6): 812-9. https://doi.org/10.1212/01.wnl.0000176753.45410.8b

13. Olek MJ, Howard J. Clinical course and classification of multiple sclerosis. https://www.uptodate.com/contents/ clinical-presentation-course-and-prognosis-of-multiplesclerosis-in-adults. Accessed May 2019.

14. Milinis K, Tennant A, Young CA. Spasticity in multiple sclerosis: associations with impairments and overall quality of life. Mult Scler Relat Disord 2016; 5: 34-9. https://doi.org/ 10.1016/j.msard.2015.10.007

15. Robinson RR, Dietz AK, Maroof AM, Asmis R, Forsthuber TG. The role of glial-neuronal metabolic cooperation in modulating progression of multiple sclerosis and neuropathic pain. Immunotherapy 2019; 11(2): 129-47. https://doi.org/10.2217/imt-2018-0153

16. Burkill S, Montgomery S, Kockum I, Piehl F, Strid P, Hillert J, et al. The association between multiple sclerosis and pain medications. Pain 2019; 160(2): 424-32. https://doi.org/ 10.1097/j.pain.0000000000001429

17. Andresen SR, Biering-Sørensen F, Hagen EM, Nielsen JF, Bach FW, Finnerup NB. Pain, spasticity and quality of life in individuals with traumatic spinal cord injury in Denmark. Spinal Cord 2016; 54(11): 973-9. https://doi.org/10.1038/ sc. 2016.46

18. van Amerongen G, Kanhai K, Baakman AC, Heuberger J, Klaassen E, Beumer TL, et al. Effects on spasticity and neuropathic pain of an oral formulation of $\Delta 9$-tetrahydro- cannabinol in patients with progressive multiple sclerosis. Clinical Therapeutics 2018; 40(9): 1467-82. https://doi.org/ 10.1016/j.clinthera.2017.01.016

\section{B. Afanasjeva, R. Balnytė}

\section{ASSOCIATION BETWEEN SPASTICITY AND NEUROPATHIC PAIN IN PATIENTS WITH MULTIPLE SCLEROSIS}

\section{Summary}

Background. Multiple sclerosis (MS) is a chronic inflammatory autoimmune demyelinating central nervous system disease. Spasticity is one of the disability causing complications in patients with this disease. Spasticity can play a role in the emergence of neuropathic pain which further aggravates the patient's daily living.

Aim. To evaluate the association between spasticity and neuropathic pain in patients with multiple sclerosis.

Methods. Patients with MS have been included in the study. The disability of patients with MS was assessed using the Expanded Disability Status Scale (EDSS). Spasticity was evaluated on both sides of the elbow and knee joints, using the modified Ashworth spasticity scale. Neuropathic pain was assessed using the neuropathic pain diagnostic questionnaire (DN4).

Results. The study involved 59 patients ( 39 women, 20 men): with relapsing-remitting MS $52(88.1 \%)$ and with progressive MS 7 (11.9\%). The higher degree of disability was estimated in patients with progressive disease form $6.36 \pm 1.38$, relapsing-remitting disease form $4.38 \pm 1.4(\mathrm{p}=0.001)$. Spasticity localization $(\mathrm{N}=35)$ : within elbow joint $2(5.71 \%)$, within knee joint $27(77.14 \%)$, within elbows and knee joint $6(17.15 \%)$. Neuropathic pain was detected in 33 patients (55.9\%). The localization of neuropathic pain $(\mathrm{N}=33)$ : in the upper extremities $5(15.15 \%)$, in the lower extremities $23(69.7 \%)$, in both extremities $5(15.15 \%)$. The nature of neuropathic pain: burning $18(30.5 \%)$, resembling of painful coldness 14 (23.7\%), resembling of electric current spreading 11 (18.6\%). Patients with spasticity more often complained of neuropathic pain $(\mathrm{r}=0.655$, $\mathrm{p}=0.0001$ ). A higher spasticity may be associated with a higher pain intensity $(r=0.536, p=0.0001)$. The localization of spasticity may be related to the location of the neuropathic pain, because the joint which was assessed with spasticity, the pain was felt in the same joint as well $(\mathrm{p}=0.0001)$.

Conclusions. The examined patients were diagnosed with MS at the middle age, the majority of subjects had the relapsingremitting disease, and disability was higher in the patients with progressive forms. Spasticity was reported in more than half of the patients with MS. Spasticity was more common in women than in men. Neuropathic pain was most commonly occurring in the lower extremities, less frequently in the upper extremities. Patients usually experienced burning pain, in some cases sensation of painful freezing and electrical shock. Patients with spasticity had a higher incidence of neuropathic pain. Greater spasticity may be associated with a higher intensity of pain and the localization of spasticity may be associated with a neuropathic pain location.

Keywords: multiple sclerosis, spasticity, neuropathic pain.

Gauta:

20190225

Priimta spaudai: 20190516 